\title{
Knowledge and awareness of malaria and mosquito biting behaviour in selected sites within Morogoro and Dodoma regions Tanzania
}

Mary M. Mathania ${ }^{1,2^{*}}$, Sharadhuli I. Kimera ${ }^{1}$ and Richard S. Silayo ${ }^{1}$

\begin{abstract}
Background: In Tanzania there has been a downward trend in malaria prevalence partly due to use of insecticidetreated bed nets for protection against Anopheles mosquitoes. However, residual malaria transmission attributed to early biting behaviour of malaria vectors is being reported. Knowledge of mosquito feeding behaviour is key to improvements in control approaches. The present study aimed to assess knowledge and awareness on malaria and malaria vectors in-Morogoro and Dodoma regions of Tanzania.
\end{abstract}

Methods: A cross sectional study was undertaken in selected sites in Morogoro and Dodoma Tanzania. A structured questionnaire was administered to 218 randomly selected households from each of which the head or second in/ charge and the most senior primary school child were interviewed.

Results: A total of 400 participants of whom $56 \%$ were females, were recruited into the study. Their ages ranged between nine and 58 years. Among the participants, $70.7 \%$ had primary school education and the rest attained secondary school (16.8\%), university/college (4.0\%) and not attended school at all (8.5\%). Fifteen per cent of the participants were employed, while $45.5 \%$ were self-employed and $39.5 \%$ were studying. Overall, $58.5 \%$ of respondents were knowledgeable of malaria and its vector. However, $78.8 \%$ were not aware that early mosquito bites can transmit malaria and $86.5 \%$ said that only midnight-biting mosquito bite was responsible for malaria transmission. The majority $(66 \%)$ of respondents visited a health facility on observing malaria symptoms while $15.8 \%$ took anti-malaria drugs without medical consultation.

Conclusion: This study has shown that Anopheles is well known as the night-biting vector of malaria. The majority of participants were not aware of changed biting behaviour of malaria-transmitting mosquitoes and that early outdoor mosquito bite is a risk of malaria transmission. School children have shown a better understanding of malaria and its vector. Therefore, more awareness of Anopheles feeding behaviour is needed.

Keywords: Malaria, Anopheles, Insecticide-treated nets (ITNs), Tanzania, Awareness

\section{Background}

Malaria is a major health concern in United Republic of Tanzania, it is a leading cause of inpatient and outpatient consultations. Nearly $93 \%$ of the mainland population lives in areas where malaria is transmitted for at least 1 month per year. Although the country has been promoting the use of long-lasting insecticide-treated nets

\footnotetext{
*Correspondence: marygiby_05@yahoo.com

1 Sokoine University of Agriculture, PO BOX 3019, Morogoro, Tanzania Full list of author information is available at the end of the article
}

(LLINs), there are still between 60,000 and 80,000 malaria attributable deaths per year, mainly children under the age 5 years and pregnant women $[1,2]$. The magnitude of the disease is more profound where knowledge and awareness of malaria and its vectors, health infrastructure and human resources for health are poor [2,3].

Vector control is the major component of the global strategy for malaria control which aims at preventing parasite transmission mainly through interventions targeting adult Anopheles mosquitoes by protecting individuals who sleep or rest indoors $[4,5]$. The use of 
pyrethroids in LLINs and indoor residual spray (IRS) has increased dramatically and become the cornerstone of malaria control programmes [4-6]. Currently the Ministry of Health and Social Welfare emphasizes a scale-up of insecticide-treated net distribution programmes under the Roll Back Malaria initiative [6]. To achieve this, the country embarked on countrywide free distribution of LLINs to make sure every household owned treated bed nets [6]. Despite the impressive success that had been achieved by use of LLINs and IRS targeting vectors that feed and rest indoor, complete elimination of malaria has rarely been achieved $[7,8]$. Still there is residual malaria transmission in different part of the world described in several studies [7-11]. Many African malaria vectors, including Anopheles gambiae s.s, Anopheles arabiensis and Anopheles funestus have shown physiological and behavioural resistance to the insecticides applied on bed nets [12]. Physiological resistance means the expression of resistance gene in mosquito trait which can cause the mosquito to contact the insecticide but not die, i.e. knock down effect. Behavioural resistance describes any modification in mosquito behaviour (feeding and resting pattern) that helps to avoid the physical contact or lethal effects of the insecticide [7]. Beside its insecticidal activity, pyrethroids cause irritations to mosquito which leads to reduction in both the rates of house entry and successful blood feeding by those which entered in the house. Furthermore, the excito-repellent effects of insecticide influenced the mosquito to change their resting and feeding behaviour, whereas before the use of LLINs malaria vectors, especially the An. gambiae complex, were endophagic and bite in the middle of the night [1315]. In many places throughout Africa a reduced indoor biting of Anopheles mosquitoes was reported to be due to ITNs and IRS use [13-15]. Malaria vectors have shown substantial change in feeding behaviour whereby these mosquitoes start biting early in the evening, before people have retired to bed where they could be protected by insecticide-treated bed nets [8-11, 16-18]. For this reason, LLINs can confer useful but incomplete personal protection. Studies done in Tanzania on humanmosquito interaction found that Anopheles biting occurred early evening where people are still active [11, 17], and this new behaviour pattern of mosquitoes may significantly increase the risk for malaria transmission. Elimination of malaria requires great focus on community knowledge, awareness and practice on malaria control strategies. Inappropriate community understanding of malaria and its vectors can draw back all effort done by malaria control programmes. Despite the enormous impact of this mosquito species behaviour, relatively little is known about community knowledge and awareness on their changed feeding behaviour.
This study was designed to assess community knowledge of malaria and malaria vector as well as awareness on changed biting behaviour of Anopheles mosquitoes in selected areas of Morogoro and Dodoma Tanzania. Understanding knowledge and awareness of malaria and its vectors will help communities to fight against malaria.

\section{Methods \\ Study area}

The study was conducted in two regions of Tanzania: Dodoma and Morogoro. The choice of study sites was based on prevalence of malaria and availability of permanent and seasonal breeding sites e.g. presence of rice paddies. Morogoro is among regions with high prevalence (13.0\%) of malaria compared to Dodoma (2.5\%) [2]. Morogoro town with a population of 350,000 is situated in eastern Tanzania $\left(6^{\circ} 49^{\prime} \mathrm{S}\right.$ and $\left.37^{\circ} 40^{\prime} \mathrm{E}\right)$ at average altitude $522 \mathrm{~m}$ above mean sea level. The study site on lower slopes of Uluguru Mountains experiences heavy rainfall from February to June. Total average annual rainfall is $783.5 \mathrm{~mm}$, mean relative humidity $72 \%$, minimum temperature $22{ }^{\circ} \mathrm{C}$, and maximum temperature $33^{\circ} \mathrm{C}$ during wet seasons. On the other hand Dodoma town has a population of 410,956 , is located $6^{\circ} 25^{\prime} \mathrm{S}$ and $35^{\circ} 75^{\prime} \mathrm{E}$. It has very low rainfall (total annual average rainfall $478.4 \mathrm{~mm}$ ), mean relative humidity $67 \%$, minimum temperature $22{ }^{\circ} \mathrm{C}$, maximum temperature $31{ }^{\circ} \mathrm{C}$ during wet seasons and is considered to be semi-arid. In Dodoma, rainfall peaks in February to April. This study was conducted during the dry season (July to August 2014).

\section{Study design and sampling procedure}

The study was a cross sectional survey. A sample of 218 households was drawn from two regions by systematic random sampling. A typical household was defined as a residential house owned or rented and occupied by one or more than one family. Household head or second incharge and senior primary school child who agreed to participate were involved in the study.

Sampled households were selected randomly whereby the first household was chosen at random, and subsequent units were obtained by calculating a sampling interval. Sampling frame was drawn from the ward executive office where list of households was obtained based on the Census 2012. A total of 218 households, 112 from Morogoro and 106 from Dodoma were involved in the study (Table 1).

\section{Data collection procedure}

A structured, pre-tested Kiswahili (as translated from English version) questionnaire consisting of open-ended and closed questions was used as data collection tool. It was designed to be completed in the presence of an 
Table 1 Description of study site and study participants

\begin{tabular}{|c|c|c|}
\hline Study site & Number of households & Number of participants ( $n$ ) \\
\hline \multirow[t]{2}{*}{ Dodoma } & 106 & Adults 136 \\
\hline & & Pupils 64 \\
\hline \multirow[t]{2}{*}{ Morogoro } & 112 & Adults 114 \\
\hline & & Pupils 86 \\
\hline Total & 218 & 400 \\
\hline
\end{tabular}

enumerator and collected after completion. For each household, two persons namely the head or second-incharge and the most senior primary school child who were available during the study were selected to fill in the questionnaire. In order to understand knowledge and awareness of malaria and mosquitoes, seven questions were asked. These questions were: what causes malaria, risk of malaria transmission, name of malaria vector, what is active mosquito biting time, potential breeding site, malaria symptoms, what to do when encountering those symptoms. Questions on awareness of changed biting behaviour of Anopheles were focused on early mosquito bites in relation to malaria transmission. For illiterate respondents, the enumerator carried out interviews using the same questionnaire. Primary school children had an additional question (Additional file 1), which was asked to mention what health information they get more frequent at school between HIV and malaria.

\section{Data processing and analysis}

Data collected were coded and entered into Excel then plugged into Epi Info 7 ready for data analysis. All questions on knowledge of mosquitoes and malaria, and awareness of changed biting behaviour of Anopheles mosquito were scored with one mark for correct answer, so as to categorize participants with 'good knowledge' zero was given for incorrect answers and those participants giving incorrect answers were categorized as having 'poor knowledge.' For awareness; participants who got correct answers were categorized as being 'aware' and those participants got incorrect answers were categorized to be "not aware". The average score was used as cut-off point.

All data were summarized into proportions and cross tabulations was done to look for association between independent and dependent variables. Chi square test $\left(x^{2}\right)$ was used to test for significance and the association was considered statistically significant if $p$ value was $<0.05$.

Logistic regression analysis was performed to test the association between binary response variables and their corresponding explanatory variables.

\section{Ethical consideration}

Ethical clearance for the studies was granted by the Sokoine University of Agriculture (SUA) Directorate for Research and Postgraduate studies. Participants were briefed on details of the study and assured confidentiality, and signed written informed consent (or oral in case illiterate respondent) to participate in the study. Anonymity was assured by identifying respondents by numbers.

\section{Results}

Demographic characteristics of study participants

A total of 218 households were visited and agreed to participate in the study. Among these, 112 households were interviewed at the Morogoro and 106 at the Dodoma. The highest proportions (41.5\%) of participants were aged $25-45$ years old. While the age group $<10-17$ years comprised $37.5 \%$, 18-24 years comprised $12.5 \%$ and age group above 45 years comprised $8.5 \%$ respondents. The ratio male to female was approximately $0.8(176 / 224)$. The majority of the heads/adult second-in-charge were self-employed. Seventy percent of participants had primary school level of education (Table 2).

\section{Knowledge of malaria, malaria vector and awareness toward biting behaviour of Anopheles mosquitoes} Table 3 presents the respondent's knowledge and awareness of malaria and malaria vector. In total, 250 household heads and 150 senior primary school children were interviewed during study period. It was

Table 2 Socio-demographic characteristics of study participants in two regions (Dodoma and Morogoro): $n=\mathbf{4 0 0}$

\begin{tabular}{lccc}
\hline Variables & Dodoma $\mathbf{n}(\%)$ & Morogoro $\mathbf{n}(\%)$ & Both $\mathbf{n}(\%)$ \\
\hline Age group (years) & & & \\
$<10-17$ & $64(32.0)$ & $86(43.0)$ & $150(37.5)$ \\
$18-24$ & $37(18.5)$ & $12(6.0)$ & $49(12.5)$ \\
$25-45$ & $71(35.5)$ & $95(47.5)$ & $166(41.5)$ \\
$>45$ & $28(14.0)$ & $7(3.5)$ & $35(8.5)$ \\
Sex & & & \\
Male & $96(48.0)$ & $80(40.0)$ & $176(44.0)$ \\
Female & $104(52.0)$ & $120(60.0)$ & $224(56.0)$ \\
Education level & & & \\
Not attended school & $34(17.0)$ & $0(0)$ & $34(8.5)$ \\
Primary school & $115(57.5)$ & $168(84.0)$ & $283(70.7)$ \\
Secondary school & $42(21.0)$ & $25(12.5)$ & $67(16.8)$ \\
College/university & $9(4.5)$ & $7(3.5)$ & $16(4.0)$ \\
Occupation & & & $60(15.0)$ \\
Employed & $28(14.0)$ & $32(16.0)$ & $182(45.5)$ \\
Self-employed & $100(50.0)$ & $82(41.0)$ & $158(39.5)$ \\
Studying & $72(36.0)$ & $86(43.0)$ &
\end{tabular}


Table 3 Respondent's knowledge of malaria, malaria vector and preventive measures in two selected cities (Dodoma and Morogoro)

\begin{tabular}{|c|c|c|c|}
\hline Variables & Dodoma n (\%) & Morogoro n (\%) & Both n (\%) \\
\hline \multicolumn{4}{|l|}{ Cause of malaria } \\
\hline Mosquito & $118(59.0)$ & $158(79.0)$ & $276(69.0)$ \\
\hline Bacteria & $22(11.0)$ & $16(8.0)$ & $38(9.5)$ \\
\hline Worms & $4(2.0)$ & $8(4.0)$ & $12(3.0)$ \\
\hline Plasmodium & $33(16.5)$ & $3(1.5)$ & $36(9.0)$ \\
\hline Others & $23(11.5)$ & $15(7.5)$ & $38(9.5)$ \\
\hline \multicolumn{4}{|c|}{ Risk of malaria transmission } \\
\hline Mosquito bite & $185(92.5)$ & $160(80.0)$ & $345(86.2)$ \\
\hline Don't know & $4(2.0)$ & $33(16.5)$ & $37(9.3)$ \\
\hline Others & $11(5.5)$ & $7(3.5)$ & $18(4.5)$ \\
\hline \multicolumn{4}{|l|}{ Name of the vector } \\
\hline Anopheles & $150(75.0)$ & $152(76.0)$ & $302(75.5)$ \\
\hline Culex & $26(13.0)$ & $20(10.0)$ & $46(11.5)$ \\
\hline Aedes & $17(8.5)$ & $12(6.0)$ & $29(7.3)$ \\
\hline Don't know & $7(3.5)$ & $16(8.0)$ & $23(5.7)$ \\
\hline \multicolumn{4}{|l|}{ Household health problem } \\
\hline Malaria & $172(86.0)$ & $175(87.5)$ & $347(86.7)$ \\
\hline $\begin{array}{l}\text { Others (typhoid, diar- } \\
\text { rhoea, UTI, fungi) }\end{array}$ & & $25(12.5)$ & $53(13.3)$ \\
\hline Don't know & $18(9.0)$ & $23(11.5)$ & $41(10.2)$ \\
\hline \multicolumn{4}{|l|}{ Malaria symptoms } \\
\hline High fever & $56(28.0)$ & $99(49.5)$ & $155(38.7)$ \\
\hline Headache & $96(48.0)$ & $53(26.5)$ & $149(37.3)$ \\
\hline Vomiting & $28(14.0)$ & $26(13.0)$ & $54(13.4)$ \\
\hline Others & $20(10.0)$ & $22(11.0)$ & $44(10.6)$ \\
\hline \multicolumn{4}{|c|}{ Action taken when encounter these symptoms } \\
\hline Hospital & $119(59.5)$ & $145(72.5)$ & $264(66.0)$ \\
\hline Pain killer & $37(18.5)$ & $25(12.5)$ & $62(15.5)$ \\
\hline Relative & $4(2.0)$ & $2(1.0)$ & $6(1.5)$ \\
\hline Traditional healer & $2(1.0)$ & $3(1.5)$ & $5(1.2)$ \\
\hline $\begin{array}{l}\text { Use anti-malarial with- } \\
\text { out checkup }\end{array}$ & $38(19.0)$ & $25(12.5)$ & $63(15.8)$ \\
\hline \multicolumn{4}{|c|}{ Early Anopheles bite transmit malaria } \\
\hline Yes & $38(19.0 \%)$ & $47(23.5 \%)$ & $85(21.2)$ \\
\hline No & $162(81.0 \%)$ & $153(76.5 \%)$ & $315(78.8)$ \\
\hline \multicolumn{4}{|c|}{ Only midnight bites responsible for malaria transmission } \\
\hline Yes & $166(83.0)$ & $179(89.5)$ & $345(86.5)$ \\
\hline No & $34(17.0)$ & $21(10.5)$ & $55(13.5)$ \\
\hline \multicolumn{4}{|c|}{ Methods used for personal protection } \\
\hline LLINS & $138(69.0)$ & $146(73.0)$ & $284(71.0)$ \\
\hline IRS & $4(1.0)$ & $0(0)$ & $4(1.0)$ \\
\hline Mosquito coils & $30(15)$ & $21(10.5)$ & $51(12.8)$ \\
\hline Mosquito spray & $18(9.0)$ & $29(14.5)$ & $47(11.8)$ \\
\hline Others & $10(5.0)$ & $4(2.0)$ & $14(3.4)$ \\
\hline \multicolumn{4}{|l|}{ For school children } \\
\hline \multicolumn{4}{|c|}{ What health information do you get more frequent at school } \\
\hline HIV & $48(70.5)$ & $75(75.5)$ & $123(73.2)$ \\
\hline Malaria & $20(29.5)$ & $25(25.0)$ & $45(26.8)$ \\
\hline
\end{tabular}

found that majority of respondents confused causation and malaria transmission risk, only $9.0 \%$ participants correctly mentioned plasmodium as a causative agent for malaria while the remainder said malaria is caused by mosquitoes, bacteria, worms and other factors (69.0, 9.5, 9.0, and $9.5 \%$ respectively). Majority of respondents $(86.2 \%)$ correctly associated malaria transmission with mosquito bites. When asked to name the vector transmitting malaria, $75.5 \%$ of respondents correctly mentioned Anopheles while 11.5 and $7.3 \%$ mentioned Culex and Aedes respectively and $5.7 \%$ indicated they did not know. With respect to perceived health problems in their households, $86.7 \%$ of respondents mentioned malaria as number one disease, while $13.3 \%$ of participants said typhoid, diarrhoea, UTI (Urinary Tract Infection) and fungal infection were other health problems in their family. Symptoms such as headache (38.7 \%), high fever (37.3\%), and vomiting (13.4\%) were three most frequently mentioned sign and symptoms of malaria. Few participants pointed out joint pain and shivering (5.3\%) as other signs and symptoms of malaria. Sixty-six percent of respondent said they go to hospital when they encounter such symptoms while $15.8 \%$ reported to use anti-malarial without laboratory checkup. Regular use of bed nets for prevention of malaria was mentioned by $71.0 \%$ of the respondents, while other mentioned measures used to prevent mosquito bites were mosquito coils (12.8\%), mosquito spray $(11.8 \%)$ and other (3.4\%) (Wearing long sleeved cloths, burning local herbs).

With regards to awareness of biting behaviour of Anopheles mosquitoes, $64.5 \%$ of study participants were not aware of changed feeding behaviour of malaria vectors. The majority of participants $78.8 \%$ were not aware that early evening Anopheles bite can transmit malaria. Most $86.5 \%$ participants believe that only midnight mosquito bites are responsible for malaria transmission. Health Centre was mentioned by adult participants as appropriate place to get health information whereas most schoolchildren pointed radio, television and school as the source of information (Fig. 1).

Furthermore, schoolchildren were asked to mention which health subject was taught regularly, Majority of pupils (73.2 \%) declared that HIV/AIDS was the subject frequently taught more than malaria (Table 3 ).

\section{Correct knowledge on malaria, malaria vectors and mosquito biting risk}

Figures 2, 3 and 4 presents different responses between binary variables based on correct knowledge on mosquito breeding sites, risk of malaria transmission, identification of mosquito pictures as well as awareness on malaria vector control methods. 


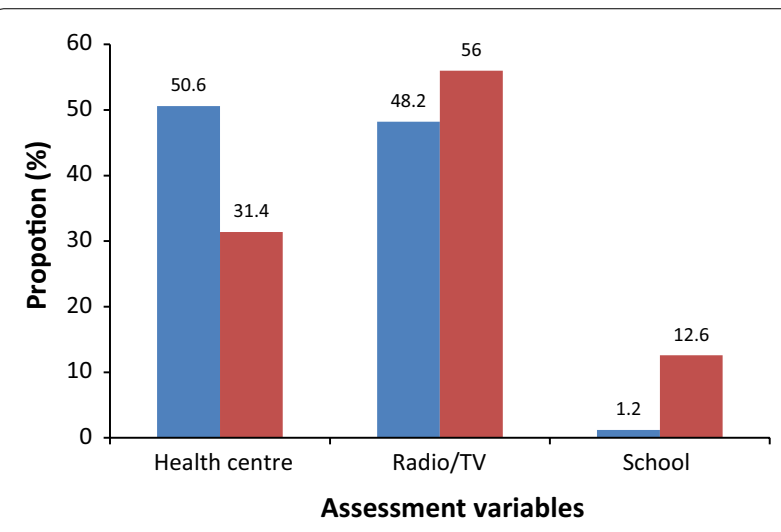

Fig. 1 Preferred source of information on malaria and its vectors by study participants (in Blue adults; in Red school children)

\section{Age}

The results in Fig. 2 shows that school children had more knowledge on mosquito breeding site compared to adult respondents $\left(\mathrm{p}=0.000009, \chi^{2}=19.79\right)$. Moreover, more school children correctly identified adult and larval mosquito pictures than adults $\left(p=0.002, \chi^{2}=9.65\right)$. Similarly, majority of school children had correct knowledge on outdoor mosquitoes in relation to risk of malaria transmission. There were no significant differences on awareness of malaria control methods, correct knowledge on midnight mosquito bites, and malaria transmission risk by early evening mosquito bites between age groups $(\mathrm{p}>0.05)$. Logistic regression shows that lower age is significantly associated with knowledge on mosquito breeding sites $(\mathrm{OR}=2.46$, $95 \%$ CI 1.5-3.9, $\mathrm{p}=0.0002)$ but other variables were not associated with age (Fig. 2).

\section{Education}

Figure 3 shows that literate respondents had more knowledge of mosquito breeding sites compared to illiterate respondents $\left(\mathrm{p}=0.0025, \chi^{2}=9.12\right)$. Literate respondents correctly identified adult and larval mosquito pictures than illiterates $\left(\mathrm{p}=0.00056, \chi^{2}=11.8\right)$. The majority literate respondents had correct knowledge on outdoor mosquitoes in relation to risk of malaria transmission ( $\mathrm{p}=0.0016, \chi^{2}=9.9$ ). Furthermore, the results show that awareness of malaria control and prevention methods was higher in literate than illiterate respondents $\left(\mathrm{p}=0.00021, \chi^{2}=13.69\right)$. There were no significant differences between literate and illiterate respondents on correct knowledge of midnight mosquito bites, as well as knowledge of malaria transmission risk by early evening mosquito bites ( $\mathrm{p}>0.05)$. Logistic regression shows that education (literate) is significantly associated with awareness of malaria vector control and prevention methods (OR 3.9, $95 \% \mathrm{CI}$ $1.8-8.2, \mathrm{p}=0.0003)$. Other response variables were not associated with education (Fig. 3).

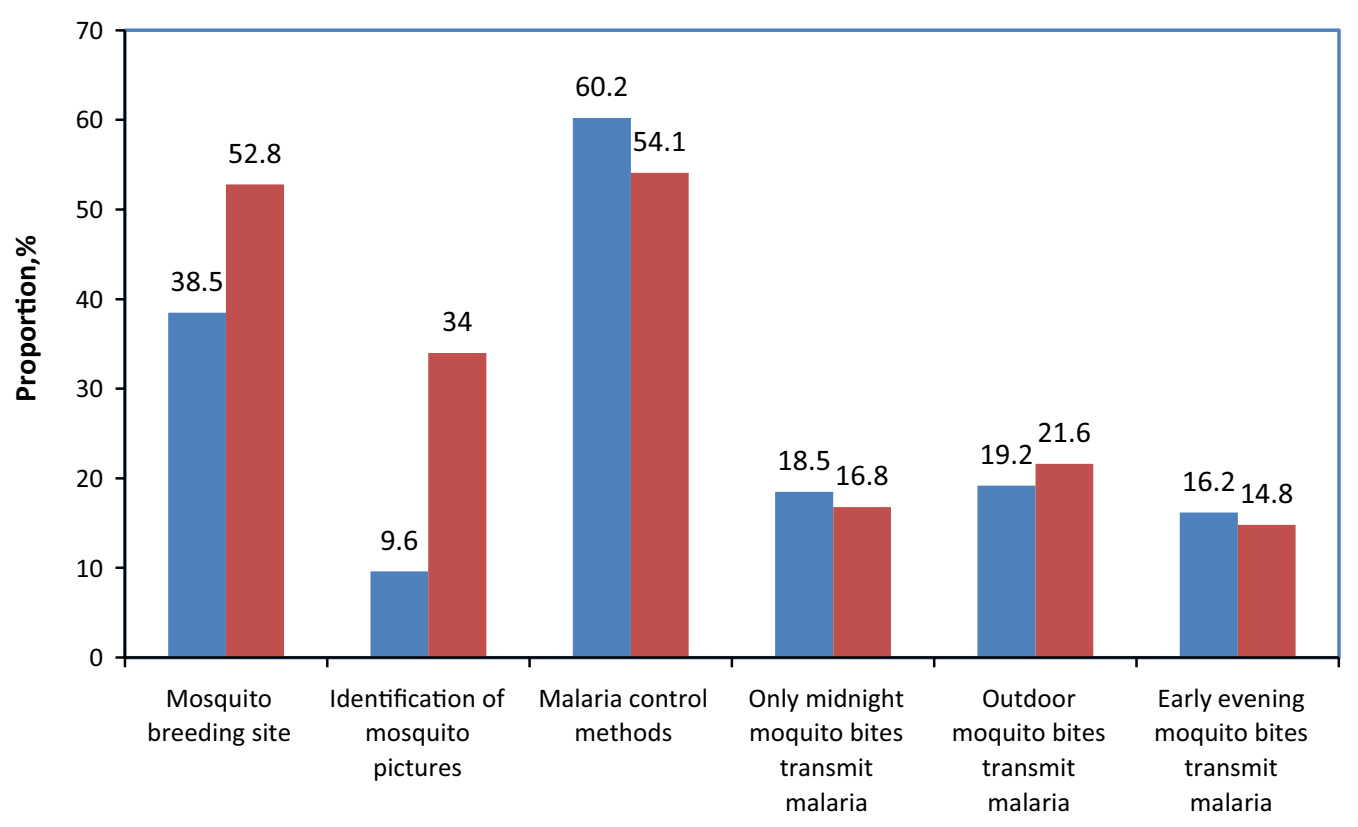

Assessment variables

Fig. 2 Correct knowledge on mosquito and malaria transmission risk by age category (in Blue adults; in Red school children) 


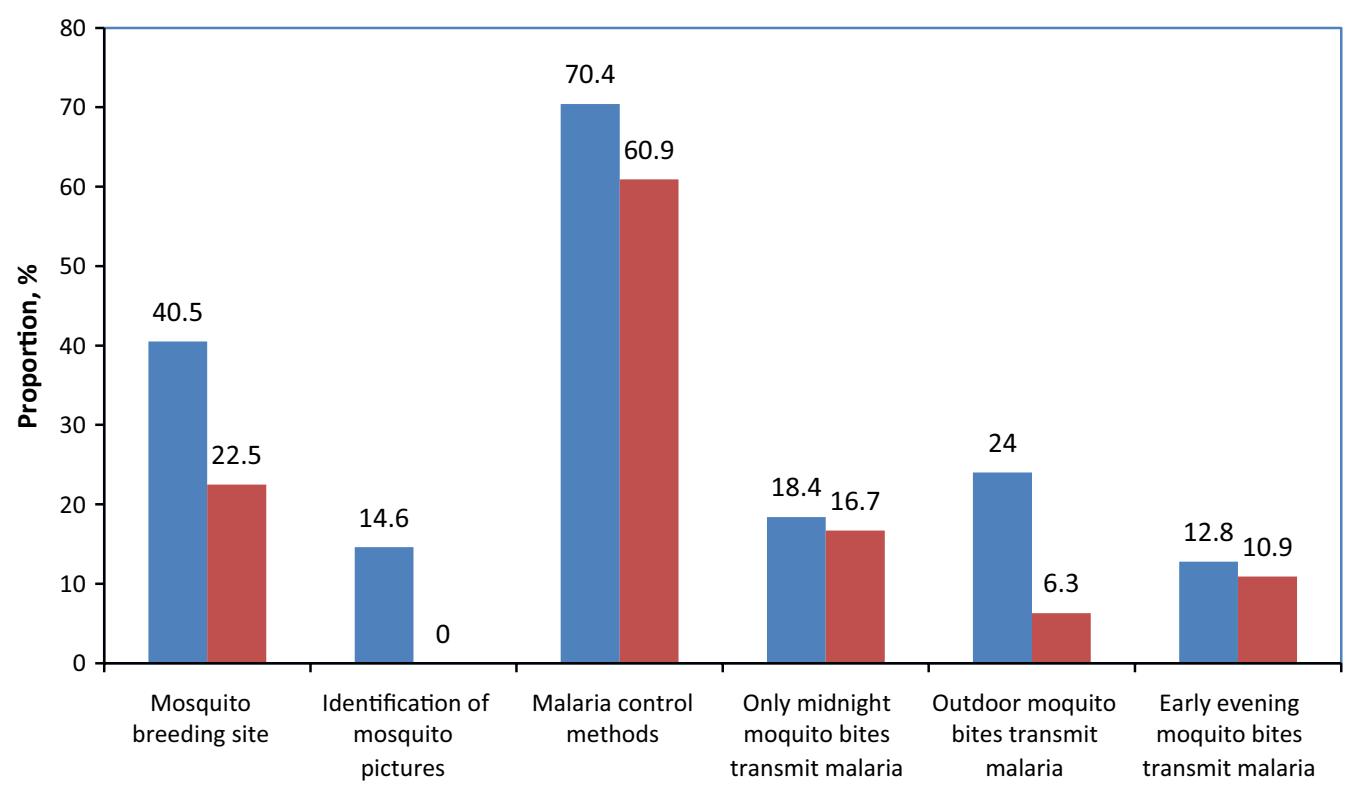

\section{Assessment variables}

Fig. 3 Correct knowledge on mosquito and malaria transmission risk by education level (in Blue literate; in Red illiterate)

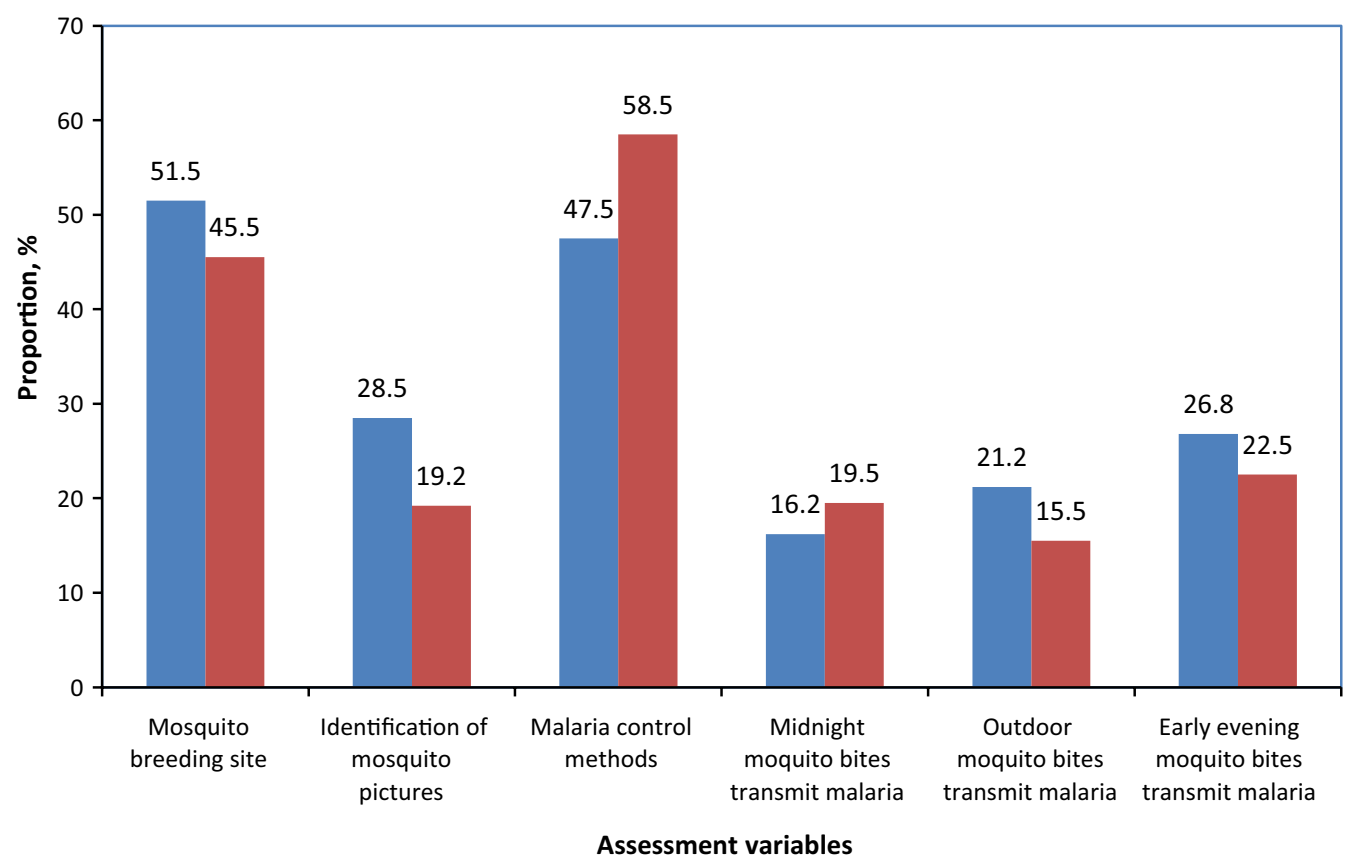

Fig. 4 Correct knowledge on mosquito and malaria transmission risk by study location (region) (in Blue Dodoma; in Red Morogoro) 


\section{Study location (Region)}

The results in Fig. 4 shows that there were no significant differences between the study locations for most of response variables investigated $(\mathrm{p}>0.05)$. However more Dodoma than Morogoro respondents had correct knowledge related to risk of malaria transmission by outdoor mosquitoes ( $\left.\mathrm{p}=0.04, \chi^{2}=4.3\right)$ (Fig. 4).

\section{Discussion}

This study investigated the knowledge and awareness on malaria and assesses the community understanding on changed feeding behaviour of Anopheles mosquitoes. Findings of this study indicate that malaria is a public health problem in many households. More respondents had good knowledge on malaria transmission risk, signs and symptoms. Despite the confusion observed among respondents on cause and transmission risk, majority pointed out the role of mosquito in malaria transmission by associating malaria with mosquito bite. The observed better knowledge about vector transmission risks may have been influenced by information, education and communication (IEC) facilities, which the respondents are exposed. Several studies have reported similar findings in malaria endemic areas [19-25]. Like elsewhere in Africa, the study participants identified malaria mainly on the basis of the symptoms of headache, high fever and vomiting, these findings conform to previous studies [20, 23-25]. The health centre was most preferred by adult participants, whereas more schoolchildren pointed radio, television and school as the source of information. Frequent utilization of health centre by adults in seeking health care and time spent at home by schoolchildren after school hours could explain the reason of their choice. This finding is in line with study done by Edson and Kayombo [26]. Despite better understanding of malaria transmission risk, signs and symptoms, the study participants demonstrated knowledge gap on mosquito breeding sites by stating that garbage and long grasses were potential breeding sites for malaria vector. A similar finding was reported in Pune district, India, where the majority of study participants reported garbage as breeding sites for malaria vector [27]. Many scholars have suggested source reduction and environmental management to be incorporated in malaria integrated programmes [28-31]. In the present study, participants demonstrated low level of knowledge on malaria breeding sites. Thus the public health education intervention programs should design health package which will cover existing knowledge gap as the country has started to encourage people to concentrate in source reduction and environmental management.

Interestingly, when the participants were given pictures of different mosquito species about quarter of participants correctly identified pictures of adult and larval stage of Anopheles mosquitoes. When further analysis was done, schoolchildren scored higher than adults. Health information given to pupils at school could explain the difference of this score. Although majority of pupils did not point out school as main source of malaria information, this study had realized that schoolchildren have better knowledge on malaria and mosquitoes than adults. Perhaps this findings could alarm malaria intervention officers to involve school teachers in malaria intervention programmes because children are enthusiastic to practice what they have learnt [26]. Since most children in Tanzania attend day school they could be a good channel for disseminating health information among household members when they go back home. What is important is to empower school teachers with appropriate health knowledge i.e. malaria through seminars and other communication means. Furthermore schoolchildren declared to be taught HIV/AIDS more than malaria, while malaria was mentioned by majority of participants to be the number one disease among top five diseases in their households. This observation would call for revision of school curriculum so that malaria and HIV/AIDS lessons could be given the same strength in primary school teachings.

Many studies have reported insecticidal pressure, which selectively caused behavioural adaptation of mosquitoes in response to indoor interventions (i.e. LLINS and IRS). This behaviour reduced the density of endophagic mosquitoes to relative more early outdoor feeding behaviour which coincides with human outdoor activities exposing people to residual malaria transmission $[8-11,16,17,32,33]$. The present study found that majority of participants was not aware that Anopheles mosquitoes can bite early evening and these bites are responsible for residual malaria transmission. This could be the outcome of the constant message carried on television and radio pointing malaria as a disease transmitted by a midnight-biting mosquito, thus more than $70 \%$ of participants used LLINs as their personal protection against mosquito bite than other methods. The use of insecticide-treated nets (ITNs) has been reported by many studies as the major recognized method of personal protection against mosquitoes bite in malaria endemic areas [20, 22, 23, 34, 35]. Although ITN use still provides useful protection, its protective efficacy is limited to those who sleep under ITNs and exclude those who are actively outdoors. Therefore, health authorities should impart knowledge to the community about changed feeding behaviour of malaria vectors so that people can protect themselves against early outdoor mosquito bites. To fight against early outdoor bites, which cause residual malaria transmission, additional important options like 
mosquito sprays and coils, wearing long sleeved cloths, larviciding and environmental management can be used to complement ITNs and IRS interventions.

\section{Conclusion and recommendation}

In this study, respondents showed moderate understanding of malaria and its vectors although knowledge and awareness of breeding sites and mosquito biting times was poor. School children have shown good understanding of malaria and its vectors; therefore there is a need to empower teachers with appropriate health information including malaria so that they can deliver malaria information to the pupils. School children are future generation so teachers-school children partnership will play a great role in malaria control strategies. Residual malaria transmission is a new challenge which is sufficiently intense across most of the tropical countries which render malaria elimination to be unfeasible, thus information, educational and communication (ICE) facilities, such as television, radio, posters, schools, health centre could be used to disseminate information of changed feeding behaviour of malaria vector so that people can protect themselves against early outdoor mosquito bite by using mosquito repellents, long sleeved cloths and environmental manipulations.

\section{Additional file}

Additional file 1. Household questionnaire.

\section{Authors' contributions}

MMM was involved in all study processes including design, data collection, analysis, and interpretation of results, as well as drafting of the manuscript. RSS was involved in study design supervision and manuscript drafting. SIK participated in study design, data analysis and manuscript revision. All authors read and approved the final manuscript.

\section{Author details \\ 1 Sokoine University of Agriculture, PO BOX 3019, Morogoro, Tanzania. \\ ${ }^{2}$ St. John's University of Tanzania, PO BOX 40, Dodoma, Tanzania.}

\section{Acknowledgements}

We express our sincere thanks to Sokoine University of Agriculture, St John's University of Tanzania and INTRA-ACP project for their academic and financial support of the studies. Drs Elifuraha B Mngumi and Joseph Mdachi are thanked for their valuable comments on statistical analysis. We are grateful to research assistant Mr. Hamis Nyoni (enumerator) and to households who participated in the study. Our immense thanks go to all Sokoine University of Agriculture staff who participated in presentation of the findings from this study and gave their valuable comments. We also acknowledge the moral and financial support received from Gibson Frank Mawalla, spouse of MMM.

\section{Competing interests}

The authors declare that they have no competing interests.

Received: 26 November 2015 Accepted: 10 May 2016

Published online: 23 May 2016

\section{References}

1. Ministry of Health. Midterm analytical review of performance of the health sector strategic plan III 2009-2015. Available http://www.who.int/ healthinfo/country/TZ_AnalyticalReport_2013. Accessed Feb 2016.

2. Measure DHS Project. Tanzania HIV/AIDS and malaria indicator survey 2011-12: Key findings. Dar es Salaam, Tanzania Commission for AIDS, National Bureau of Statistics, ICF International (http://dhsprogram.com/ pubs/pdf/SR196/SR196.pdf).

3. Mboera LE, Ipuge Y, Kumalija CJ, Rubona J, Perera S, Masanja H, et al. Midterm review of national health plans: an example from the United Republic of Tanzania. Bull World Health Organ. 2015:93:271-8.

4. Killeen GF, Seyoum A, Sikaala C, Zomboko AS, Gimnig JE, Govella NJ, et al. Eliminating malaria vectors. Parasit Vectors. 2013;6:172.

5. Moonen B, Cohen JM, Snow RW, Slutsker L, Drakeley C, Smith DL, et al. Operational strategies to achieve and maintain malaria elimination. Lancet. 2010;376:1592-603.

6. Partnership Roll Back Malaria. Scaling up insecticide treated netting programmes in Africa: a strategic framework for coordinated national action. Geneva: World Health Organization; 2005. p. 26.

7. Ranson H, N'Guessan R, Lines J, Moiroux N, Nkuni Z, Corbel V. Pyrethroid resistance in African anopheline mosquitoes: what are the implications for malaria control? Trends Parasitol. 2011:27:91-8.

8. Russell TL, Beebe NW, Cooper RD, Lobo NF, Burkot TR. Successful malaria elimination strategies require interventions that target changing vector behaviours. Malar J. 2013;12:56.

9. Braimah N, Drakeley C, Kweka E, Mosha F, Helinski M, Pates H, et al. Tests of bednet traps (Mbita traps) for monitoring mosquito populations and time of biting in Tanzania and possible impact of prolonged insecticide treated net use. Int J Trop Insect Sci. 2005;25:208-13.

10. Killeen GF. Characterizing, controlling and eliminating residual malaria transmission. Malar J. 2014;13:330.

11. Russell TL, Govella NJ, Azizi S, Drakeley CJ, Kachur SP, Killeen GF. Increased proportions of outdoor feeding among residual malaria vector populations following increased use of insecticide-treated nets in rural Tanzania. Malar J. 2011;10:80

12. Smith DL, Cohen JM, Chiyaka C, Johnston G, Gething PW, Gosling R, et al. A sticky situation: the unexpected stability of malaria elimination. Philos Trans R Soc Lond B Biol Sci. 2013;368:20120145.

13. Reddy MR, Overgaard HJ, Abaga S, Reddy VP, Caccone A, Kiszewski AE, et al. Outdoor host seeking behaviour of Anopheles gambiae mosquitoes following initiation of malaria vector control on Bioko Island Equatorial Guinea. Malar J. 2011;10:184.

14. Pates H, Curtis C. Mosquito behavior and vector control. Annu Rev Entomol. 2005:50:53-70.

15. Molina R, Benito A, Blanca F, Roche J, Otunga B, Alvar J. The anophelines of equatorial guinea: ethology and susceptibility studies. Res Rev Parasitol. 1996;56:105-10

16. Cano J, Berzosa PJ, Roche J, Rubio JM, Moyano E, Guerra-Neira A, et al. Malaria vectors in the Bioko Island (Equatorial Guinea): estimation of vector dynamics and transmission intensities. J Med Entomol. 2004:41:158-61.

17. Geissbühler Y, Chaki P, Emidi B, Govella NJ, Shirima R, Mayagaya V, et al. Interdependence of domestic malaria prevention measures and mosquito-human interactions in urban Dar es Salaam Tanzania. Malar J. 2007;6:126.

18. Ilboudo-Sanogo E, Cuzin-Ouattara N, Diallo DA, Cousens SN, Esposito F, Habluetzel A, et al. Insecticide-treated materials, mosquito adaptation and mass effect: entomological observations after five years of vector control in Burkina Faso. Trans R Soc Trop Med Hyg. 2001;95:353-60.

19. Ahmed SM, Haque R, Haque U, Hossain A. Knowledge on the transmission, prevention and treatment of malaria among two endemic populations of Bangladesh and their health-seeking behaviour. Malar J. 2009;8:173

20. Mazigo HD, Obasy E, Mauka W, Manyiri P, Zinga M, Kweka EJ, et al. Knowledge, attitudes, and practices about malaria and its control in rural northwest Tanzania. Malar Res Treat. 2010;2010:794261.

21. Mboera LE, Mlozi MR, Senkoro KP, Rwegoshora RT, Rumisha SF. Malaria and agriculture in Tanzania: Impact of land-use and agricultural practices on malaria burden in Mvomero District. National Institute for Medical Research: Dar es Salaam; 2007. p. 114. 
22. Hlongwana KW, Mabaso ML, Kunene S, Govender D, Maharaj R. Community knowledge, attitudes and practices (KAP) on malaria in Swaziland: a country earmarked for malaria elimination. Malar J. 2009;8:29.

23. Kinung'hi SM, Mashauri F, Mwanga JR, Nnko SE, Kaatano GM, Malima R, et al. Knowledge, attitudes and practices about malaria among communities: comparing epidemic and non-epidemic prone communities of Muleba district, North-western Tanzania. BMC Public Health. 2010;10:395.

24. Dunyo SK, Afari EA, Koram KA, Ahorlu CK, Abubakar I, Nkrumah FK. Health centre versus home presumptive diagnosis of malaria in southern Ghana: implications for home-based care policy. Trans R Soc Trop Med Hyg 2000;94:285-8

25. Kamugisha ML, Maxwell C, Curtis CF. Characteristics of malaria among children living in lowland and highlands of Muheza Dirtrict, north-east Tanzania. Tanzania Journal of Health Research. 2005;7:67-72.

26. Edson F, Kayombo EJ. Knowledge on malaria transmission and its prevention among schoolchildren in Kyela District, South Western Tanzania. Tanzania J Health Res. 2007;9:207-10.

27. Madne G, Jindal AK, Patel BB, Sharma R, Kant R. Knowledge and practices concerning malaria in rural community of Pune district. Med J Dr DY Patil Univ. 2014;7:450-3.

28. Killeen GF, Fillinger U, Kiche I, Gouagna LC, Knols BG. Eradication of Anopheles gambiae from Brazil: lessons for malaria control in Africa? Lancet Infect Dis. 2002;2:618-27.
29. Utzinger J, Tanner M, Kammen DM, Killeen GF, Singer BH. Integrated programme is key to malaria control. Nature. 2002:419:431.

30. Keiser J, Singer $\mathrm{BH}$, Utzinger J. Reducing the burden of malaria in different eco-epidemiological settings with environmental management: a systematic review. Lancet Infect Dis. 2005;5:695-708.

31. Utzinger J, Tozan Y, Singer BH. Efficacy and cost-effectiveness of environmental management for malaria control. Trop Med Int Health. 2001;6:677-87.

32. Killeen GF, Kihonda J, Lyimo E, Oketch FR, Kotas ME, Mathenge E, et al. Quantifying behavioural interactions between humans and mosquitoes: evaluating the protective efficacy of insecticidal nets against malaria transmission in rural Tanzania. BMC Infect Dis. 2006;6:161.

33. Sougoufara S, Diédhiou SM, Doucouré S, Diagne N, Sembène PM, Harry $\mathrm{M}$, et al. Biting by Anopheles funestus in broad daylight after use of longlasting insecticidal nets: a new challenge to malaria elimination. Malar J. 2014;13:125.

34. Takken W. Do insecticide-treated bednets have an effect on malaria vectors? Trop Med Int Health. 2002;7:1022-30

35. Govella NJ, Okumu FO, Killeen GF. Insecticide-treated nets can reduce malaria transmission by mosquitoes which feed outdoors. Am J Trop Med Hyg. 2010;82:415-9.

\section{Submit your next manuscript to BioMed Central and we will help you at every step:}

- We accept pre-submission inquiries

- Our selector tool helps you to find the most relevant journal

- We provide round the clock customer support

- Convenient online submission

- Thorough peer review

- Inclusion in PubMed and all major indexing services

- Maximum visibility for your research

Submit your manuscript at www.biomedcentral.com/submit 